\title{
Effects of Alloying Elements (Cr, Mn) on Corrosion Properties of the High-Strength Steel in 3.5\% $\mathrm{NaCl}$ Solution
}

\author{
Bomi Kim $\mathbb{D}^{1},{ }^{1}$ Soojin Kim $\mathbb{D}^{2}{ }^{2}$ and Heesan Kim $\mathbb{D}^{1}$ \\ ${ }^{1}$ Department of Materials Science and Engineering, Hongik University, 2639 Sejong-ro, Jochiwon-eup, Sejong 339-701, \\ Republic of Korea \\ ${ }^{2}$ University of Alabama School of Medicine, 510 20th St. S., Birmingham, AL 35210, USA \\ Correspondence should be addressed to Heesan Kim; heesan1118@gmail.com
}

Received 30 August 2017; Revised 23 October 2017; Accepted 31 October 2017; Published 15 February 2018

Academic Editor: María V. Biezma

Copyright (c) 2018 Bomi Kim et al. This is an open access article distributed under the Creative Commons Attribution License, which permits unrestricted use, distribution, and reproduction in any medium, provided the original work is properly cited.

Effects of chromium and manganese as alloying elements on corrosion resistance of carbon steel were examined using evaluation of corrosion resistance in $60^{\circ} \mathrm{C} \mathrm{NaCl}$ solution with a weight loss test, polarization test, analysis of rust with X-ray diffractometer, Raman spectroscopy, transmission electron microscopy, energy dispersive spectroscopy, and electron energy loss spectroscopy. The weight loss behavior conformed to a typical parabolic law, and the oxidation state of iron in rust was higher along the fast pathway but was disproportionate to the distance from the alloy/AR interface. It suggests that the corrosion process of the alloys was controlled by transport of oxygen to the rust layer. The improvements in corrosion resistance of $18 \mathrm{Mn}$ and $18 \mathrm{Mn} 5 \mathrm{Cr}$ resulted from both the refinement of grain in adherent rust (AR) and the increase of the amounts of goethite in nonadherent rust (NAR) by chromium and manganese. Especially, the effectiveness of chromium on corrosion resistance was also related to the refinements of grain in AR and the amounts of goethite in NAR. The Tafel extrapolation method was inadequate to measure the instantaneous corrosion rate of steels with various alloying elements and immersion periods because of the difference in electrochemical reduction rates of rust, depending on its constituent.

\section{Introduction}

High manganese steels with high strength and toughness were developed to satiate the need for a material with superb physical properties in response to energy crisis and carbon dioxide release restriction [1]. However, even recently, relevant studies on the effects of manganese on corrosion resistance of steel have been comparatively minimal [2-5]. Particularly, the effects of manganese on corrosion resistance of steel during the exposure to chloride-containing environments have been reported inconsistently [4, 6-12].

In a previous study, Melchers [13, 14] proposed a model on the corrosion process of carbon steel. Before microbiological-induced corrosion (MIC) or pitting corrosion does not occur, the model consists of two stages depending on the rate-determining step: reactions on its metal surface for the first stage and diffusion of oxygen through rust for the second stage. Because the model remains in the second stage for the most of the total exposure period, we believe that corrosion resistance of carbon steels during a long-term exposure greatly depends on the rust as it serves as a medium for oxygen penetration. The long-term exposure test has shown that the corrosion rates for the rust components are less than $0.01 \mathrm{~mm} / \mathrm{yr}$, as shown in $(1)[15,16]$ :

$$
\begin{gathered}
\frac{\alpha}{\gamma^{*}}>1, \\
\text { or } \frac{s+\beta}{\gamma^{*}}<0.5,
\end{gathered}
$$

where $\alpha, s, \gamma$, and $\beta$ are the mass concentrations of goethite, spinel oxide, lepidocrocite, and akaganeite, respectively, and $\gamma^{*}$ is the total of $s, \gamma$, and $\beta$. The first equation demonstrates the effect of the amount of ultrafine-grained goethite on the rust protectiveness. The second equation illustrates the penetration of corrosive species through the defects in akaganeite and spinel oxide $[15,17,18]$. 
TABLE 1: Chemical composition of the experimental alloys.

\begin{tabular}{lccccrr}
\hline \multirow{2}{*}{ Name } & Phase(s) & \multicolumn{3}{c}{ Chemical composition (\% wt.) } \\
& & $\mathrm{C}$ & $\mathrm{Mn}$ & $\mathrm{Cr}$ & $\mathrm{Ni}$ & \multicolumn{2}{c}{ Fe } \\
\hline REF(API60) & $\alpha$ +bainite & 0.067 & 1.6 & 0.02 & \multicolumn{2}{c}{ Balance } \\
$18 \mathrm{Mn}$ & $\gamma$ & 0.6 & 18.4 & $<0.005$ & $<0.005$ & Balance \\
$18 \mathrm{Mn} 5 \mathrm{Cr}$ & $\gamma$ & 0.6 & 18.5 & 5.1 & $<0.005$ & Balance \\
\hline
\end{tabular}

In general, the transport of oxygen through rust depends on its grain size, crystal structure, chemical stability, and porosity [19-24], which explains the dependency of corrosion resistance on iron oxide or oxyhydroxide. According to the Melchers model, during the initial state of the first stage, steels are oxidized to produce various forms of dissolved ferrous ion or precipitated ferrous hydroxide. The various forms of ferrous ion are chemically or electrochemically oxidized by oxygen to produce different types of ferric oxyhydroxide, maghemite, or hematite. With the elapsed time, the thickened rust layer impedes the transport of oxygen to the steel surface. During this period, various forms of ferric oxyhydroxide may reduce to magnetite [25, 26]: incorporation of ferrous ion into ferric oxyhydroxide [27], slow oxidation of ferrous hydroxide via green rust (GR) [28], or reaction of the dissolved ferric oxyhydroxide with dissolved ferrous hydroxide [29, 30]. The first process occurs in rust, and the other processes occur at the rust/solution interface or at rust near the solution. As an alloying element, manganese not only impedes the formation of magnetite $[31,32]$ but also encourages the formation of refined goethite. Chromium hinders magnetite's nucleation [33] and growth [34], while it promotes the nucleation [33] and growth [35] of goethite and refinement of grain [36]. Both manganese and chromium improve corrosion resistance of steel; however, chromium has a greater effect than manganese [36].

The effects of manganese and chromium on corrosion resistance [37] of high manganese steels were studied by examining rust properties with X-ray diffraction (XRD), Raman spectroscopy, energy dispersive spectroscopy (EDS) $[4,5]$, and electron energy loss spectroscopy (EELS) adjunct to transmission electron microscopy (TEM).

\section{Experimental Procedure}

2.1. Preparation of Specimen. The ingots (API60, $18 \mathrm{Mn}$, and $18 \mathrm{Mn} 5 \mathrm{Cr}$ ) with chemical compositions listed in Table 1 were cast to examine the effects of corrosion resistance of carbon steel on manganese and chromium. API60 was used as a reference material and hereafter named "REF". $25 \mathrm{~kg}$ ingots were heat treated at $1150^{\circ} \mathrm{C}$ for 1.5 hours under an argon atmosphere and hot rolled to $4.5 \mathrm{~mm}$. Both surfaces of the plate were mill-machined to $3 \mathrm{~mm}$ thickness in order to remove the scale formed during the heat treatment. Then, the $3 \mathrm{~mm}$ thick plates were cut into $2 \mathrm{~cm} \times 1 \mathrm{~cm} \times 0.4 \mathrm{~cm}$ coupons for an immersion test and $1 \mathrm{~cm} \times 1 \mathrm{~cm} \times 0.4 \mathrm{~cm}$ coupons for a polarization test, respectively. All the surfaces were wet grounded with successive grade silicon carbide papers, from 200 to 600 grit, degreased with acetone, rinsed with ethanol, blow-dried, and finally kept in a desiccator.
2.2. Evaluation of Corrosion Resistance. The weight loss test and polarization test were conducted to evaluate corrosion resistance of the experimental alloys. The tests were carried in $3.5 \% \mathrm{NaCl}$ aqueous solution at a constant temperature of $60^{\circ} \mathrm{C}$. During the immersion test, the coupons were supported on cradles-a glass cradle with protrusions-to minimize the cradle-couple contact area. In each capped vessel, each coupon was immersed in $200 \mathrm{~mL}$ of $3.5 \% \mathrm{NaCl}$ solution. Immersion periods were $1,7,14,28$, and 56 days for REF, $18 \mathrm{Mn}$, and $18 \mathrm{Mn} 5 \mathrm{Cr}$, respectively. On every 7 th day, the solution was replaced with a fresh solution to maintain the $\mathrm{pH}$ of the solution within 0.2 . For the weight loss measurements, the rust formed on the coupon was removed, and the exposed coupon was immersed in a hydrochloric acid inhibited with hexamethylenetetramine $\left(0.025 \mathrm{M} \mathrm{C}_{6} \mathrm{H}_{12} \mathrm{~N}_{4}+5.43 \mathrm{M} \mathrm{HCl}\right)$ at room temperature in an ultrasonic bath for 5-10 minutes, according to ASTM G1 [38]. The weight measurement results were used to calculate the weight at an immersion time and mean weight loss rate as shown in

$$
\text { Mean weight loss rate }\left(t_{i}\right)=\frac{\Delta W\left(t_{i}\right)-\Delta W\left(t_{i-1}\right)}{t_{i}-t_{i-1}},
$$

where $\Delta W\left(t_{i}\right)$ is the weight loss per surficial area at immersion time $t_{i}$.

The immersion test was repeated twice under the same condition for reproducibility. If the results showed high deviations, the immersion test was repeated until credible/reliable data were obtained.

The cathodic polarization test was conducted to measure instantaneous corrosion rates $\left(i_{\text {corr }}\right)$ [39], and the anodic polarization test was performed to observe corrosion behaviors. To prepare a working electrode, the square coupons were embedded in epoxy resin [37] with an exposure area of $1 \mathrm{~cm}^{2}$, wet grounded with 600 grit silicon carbide papers, rinsed with ethanol, dried, and stored in a desiccator. A saturated calomel electrode (SCE) and a platinum mesh were used as a reference electrode and a counter electrode, respectively. The mounted coupons, from 1-day and 56-day immersion in the chloride solution, were anodically or cathodically polarized by a corrosion potential at the scan rate of $20 \mathrm{mV} / \mathrm{min}$. By linearly fitting the polarization curves around the potentials by $100 \mathrm{mV}$ lower than corrosion potentials, cathodic Tafel slopes $\left(\beta_{c}\right)$ were obtained as well as instantaneous corrosion rates.

2.3. Analysis of Rust. At the end of 56-day immersion, the coupons with their vessels were placed in the ultrasonic bath for 15-20 seconds to remove nonadherent rusts (NARs), and then, the coupons were extracted. The NARs were filtrated, 
TABLE 2: Summaries on the commercial companies and synthetic methods of iron oxides used for the standard Raman spectra.

\begin{tabular}{lcc}
\hline Iron oxide & Source & Remarks \\
\hline Magnetite & High Purity Chemicals & Powder, $<1 \mu \mathrm{m},>99 \%$ \\
Maghemite $\left(\gamma-\mathrm{Fe}_{2} \mathrm{O}_{3}\right)$ & {$[22]$} & Powder \\
Hematite $\left(\alpha-\mathrm{Fe}_{2} \mathrm{O}_{3}\right)$ & High Purity Chemicals & Powder, $<1 \mu \mathrm{m},>99 \%$ \\
Goethite $(\alpha-\mathrm{FeOOH})$ & Rare Metallic Co. Ltd. & Powder, $>99 \%$ \\
Akaganeite $(\beta-\mathrm{FeOOH})$ & {$[22]$} & Powder \\
Lepidocrocite $(\gamma-\mathrm{FeOOH})$ & High Purity Chemicals & Powder, $>99 \%$ \\
\hline
\end{tabular}

TABLE 3: Summary on the peaks observed from the Raman spectra of standard samples of iron rust.

\begin{tabular}{|c|c|c|c|c|c|c|}
\hline \multirow{2}{*}{ Standard sample } & \multicolumn{5}{|c|}{ Peak positions $/ \mathrm{cm}^{-1}$ (relative intensity) } & \multirow{2}{*}{ Remarks } \\
\hline & 1 st & 2nd & 3rd & 4th & 5 th & \\
\hline Magnetite & $286(100)$ & $396(54)$ & $222(50)$ & $640(41)^{*}$ & $475(22)$ & *Wide \\
\hline Maghemite $\left(\gamma-\mathrm{Fe}_{2} \mathrm{O}_{3}\right)$ & $286(100)$ & $396(54)$ & $222(50)$ & $640(41)^{*}$ & $475(22)$ & ${ }^{*}$ Wide; peak at 710 \\
\hline Hematite $\left(\alpha-\mathrm{Fe}_{2} \mathrm{O}_{3}\right)$ & $292(100)$ & $224(54)$ & $410(44)$ & $612(24)$ & $494(11)$ & - \\
\hline Goethite $(\alpha-\mathrm{FeOOH})$ & $386(100)$ & $301(29)$ & $548(17)$ & $482(16)$ & $245(13)$ & - \\
\hline Akaganeite $(\beta-\mathrm{FeOOH})$ & $390(100)^{*}$ & $310(87)^{*}$ & $495(26)$ & $540(22)$ & - & *Wide \\
\hline Lepidocrocite $(\gamma$-FeOOH $)$ & $250(100)$ & $378(57)$ & $530(55)$ & $347(43)$ & $308(23)$ & - \\
\hline
\end{tabular}

washed with distilled water to remove chloride, and dried at $50^{\circ} \mathrm{C}$ in an oven for 1 hour. Later, all the rusts were grounded into a homogeneous powder mixture. The extracted coupons were also washed and dried with the same procedure as the NARs in order to analyze all the adherent rusts (ARs) which were still intact with the coupons after the ultrasonic bath. $\mathrm{X}$-ray diffraction and Raman spectroscopy were performed to analyze NARs, while XRD, TEM-EDS, and EELS were conducted to analyze ARs.

The XRD measurements of the NARs were performed on a diffractometer (Digaku D/max-3A model) equipped with $\mathrm{Cu}(\mathrm{K} \alpha)$ for both qualitative and quantitative analyses. The scans were done in the range of $2 \theta$ between $10^{\circ}$ and $90^{\circ}$ at a rate of 2 degrees/min. For the qualitative analysis, $85 \%$ of the entire NARs and the reference oxides listed in Table 2 were mixed with $15 \%$ of zinc oxide. Among the reference samples in Table 2, magnetite, hematite, goethite, and lepidocrocite were purchased and the others were synthesized [22]. For quantitative analysis, zinc oxide was mixed to serve as a reference intensity. Then, to quantitatively analyze the NARs, $85 \%$ of several mixtures of the known amounts of oxides listed in Table 2 were mixed with $15 \%$ of zinc oxide, following the internal standard method [40]. From the XRD measurements, the intensities of iron oxides were expressed as a function of concentration. In terms of the qualitative analysis of the ARs, XRD measurement was performed under the same conditions as mentioned above. Two modes were used to show phase distributions along the depth direction, where one is a normal mode and the other is a thin film mode. In the thin film mode, the glance angle was fixed to $1^{\circ}$. The coupons on which ARs were formed were used without an additional preparation for XRD measurements.

The Raman spectra of pellets made from the powder were measured in a Raman II-Senterra (Bruker). It was configured with a microscope of 50x magnification. The Raman spectroscopy was excited using a laser $(785.0 \mathrm{~nm})$ with a nominal maximum output power of $1 \mathrm{~mW}$ for 20 seconds to avoid any internal structure modification of the samples. The Raman spectra of the iron oxides listed in Table 2 were measured and summarized in Table 3 to qualitatively analyze the NARs.

The ARs were analyzed by scanning transmission electron microscopy (STEM, JEM-ARM200F), and their compositions, grain sizes, crystal structures, and oxidation states within $1 \mu \mathrm{m}$ far away from an interface between the alloy and the AR were examined. With the thinned sample prepared by a focused ion beam (FIB), AR chemical composition was analyzed by energy X-ray dispersive spectroscopy (EDS); the crystal structure and grain size were analyzed by selected area electron diffraction (SAED); and the oxidation state of iron was analyzed by electron energy loss spectroscopy (EELS) according to (3) [41]:

$$
\text { Oxidation state of iron } \propto \frac{I \text {. of Fe } L_{3}}{I \text {. of Fe } L_{2}} \text {, }
$$

where $I$. of Fe $L_{i}$ is the integral intensity of the Fe $L_{i}$ edge peak.

\section{Results}

3.1. Effect of Alloying Elements on Corrosion Resistance. Figure 1 provides both weight loss and mean weight loss rate with immersion time of all the experimental alloys in 3.5\% $\mathrm{NaCl}$ solution at $60^{\circ} \mathrm{C}$. In all the alloys, weight loss increased with immersion time but the mean weight loss rate decreased, which is referred as a typical parabolic behavior hereafter. In addition, chromium and manganese, as alloying elements, showed reduced mean weight loss rates 


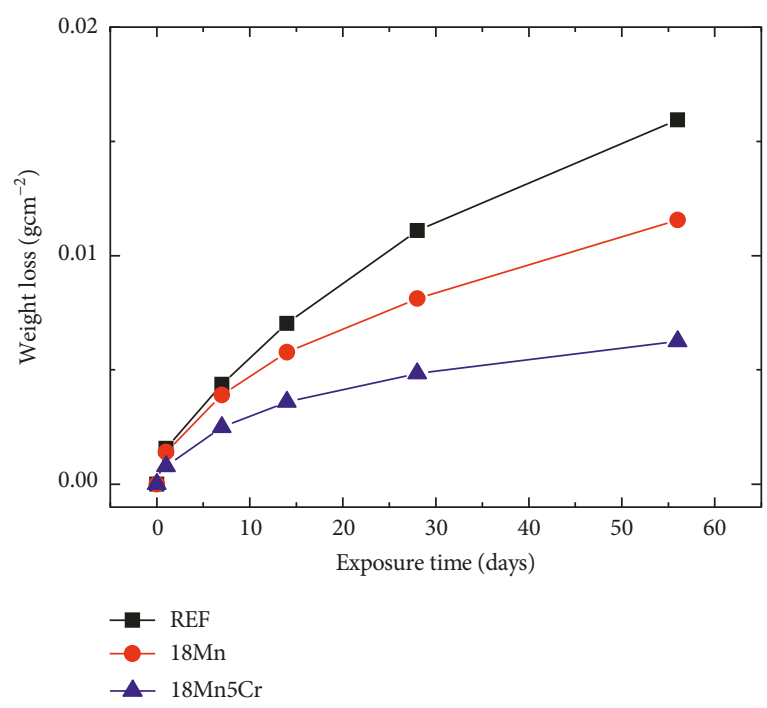

(a)

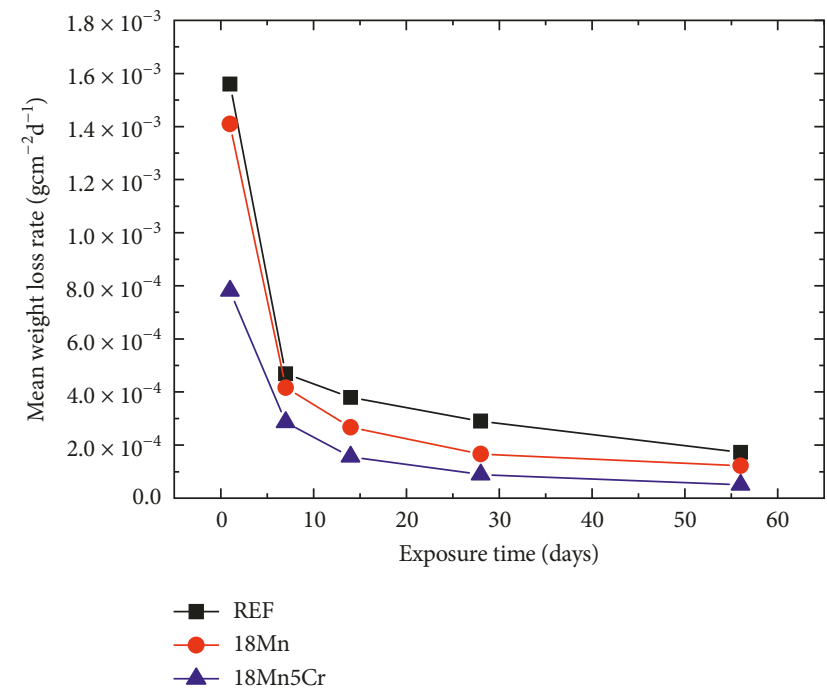

(b)

Figure 1: Weight loss versus time curves (a) and average weight loss rate versus time curves (b) of experimental alloys immersed in 3.5\% $\mathrm{NaCl}$ solution at $60^{\circ} \mathrm{C}$.

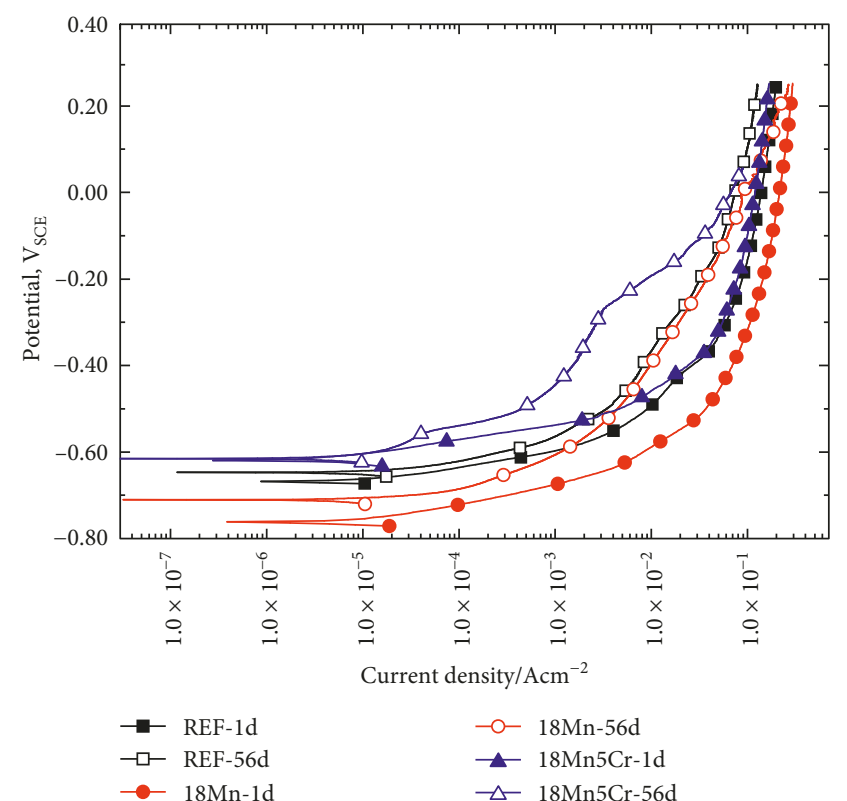

(a)

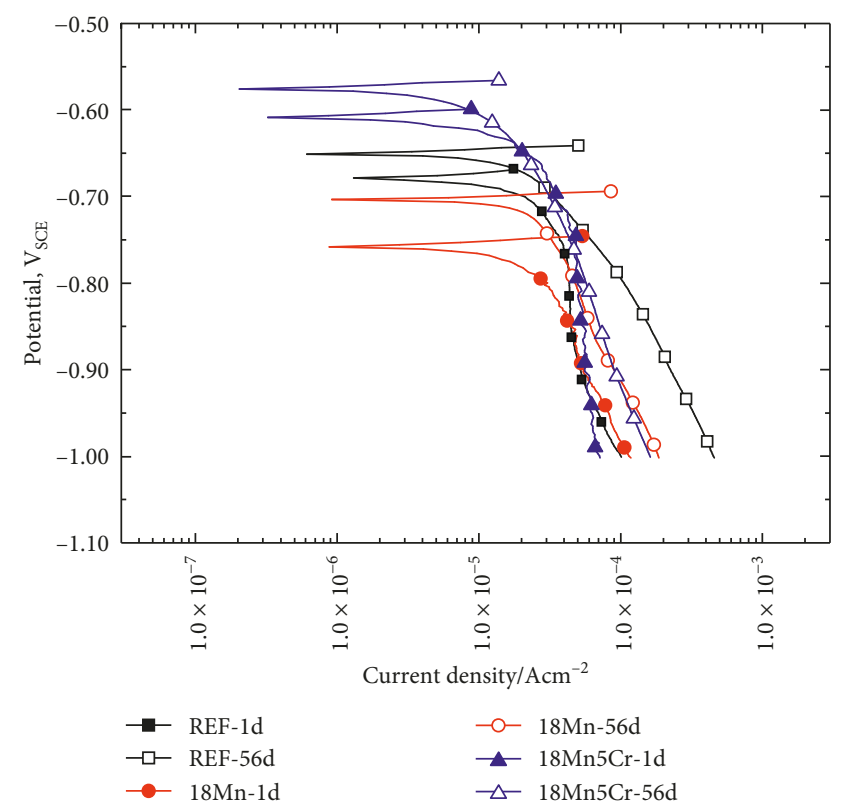

(b)

Figure 2: Anodic (a) and cathodic (b) polarization curves of experimental alloys in $3.5 \% \mathrm{NaCl}$ solution at $60^{\circ} \mathrm{C}$.

during the immersion period, while chromium improved corrosion resistance.

The anodic polarization curves in Figure 2(a) and corrosion potentials in Table 4 show that corrosion potentials were ennobled with immersion, and anodic current densities at the range of potential between corrosion potentials and $-0.1 V_{\text {SCE }}$ were reduced with immersion time. These results indicate that the decreased corrosion rate with immersion period in Table 4 is caused by the formation of rust, resulting in the change of anodic current density. In addition, the ratio of anodic currents at two different immersion periods
( 1 day and 56 days) was reduced in the following order: $18 \mathrm{Mn} 5 \mathrm{Cr}>18 \mathrm{Mn}>\mathrm{REF}$, which corresponds with the change of the mean weight loss rate shown in Figure 1(b). Hence, the results on the immersion test and polarization test suggest that both chromium and manganese aid to form more protective rust and retard the penetration of corrosive species such as oxygen [36] into the rust layer-a controlling step for corrosion. Furthermore, the result corresponds to the corrosion mechanism proposed by Melchers [13] that, during the second stage, the corrosion rate of carbon steel is controlled by the migration rate of corrosive species through 
TABLE 4: Summaries on corrosion potentials, Tafel slopes, and corrosion rates of the experimental alloys from analysis of cathodic polarization curves in Figure 2(b).

\begin{tabular}{|c|c|c|c|c|c|c|}
\hline \multirow{3}{*}{ Alloys } & \multicolumn{6}{|c|}{ Immersion time } \\
\hline & \multicolumn{3}{|c|}{1 day } & \multicolumn{3}{|c|}{56 days } \\
\hline & Corros. pot. $\left(V_{\mathrm{SCE}}\right)$ & Tafel slope $\left(\beta_{c}\right)$ & $i_{\text {corr }}\left(\mu \mathrm{A} / \mathrm{cm}^{2}\right)$ & Corros. pot. $\left(V_{S \mathrm{CE}}\right)$ & Tafel slope $\left(\beta_{c}\right)$ & $i_{\text {corr }}\left(\mu \mathrm{A} / \mathrm{cm}^{2}\right)$ \\
\hline REF & -0.679 & -0.557 & 27.8 & -0.652 & -0.209 & 25.1 \\
\hline $18 \mathrm{Mn}$ & -0.758 & -0.557 & 29.5 & -0.704 & -0.511 & 31.6 \\
\hline $18 \mathrm{Mn} 5 \mathrm{Cr}$ & -0.608 & -0.288 & 16.2 & -0.577 & -0.345 & 13.4 \\
\hline
\end{tabular}

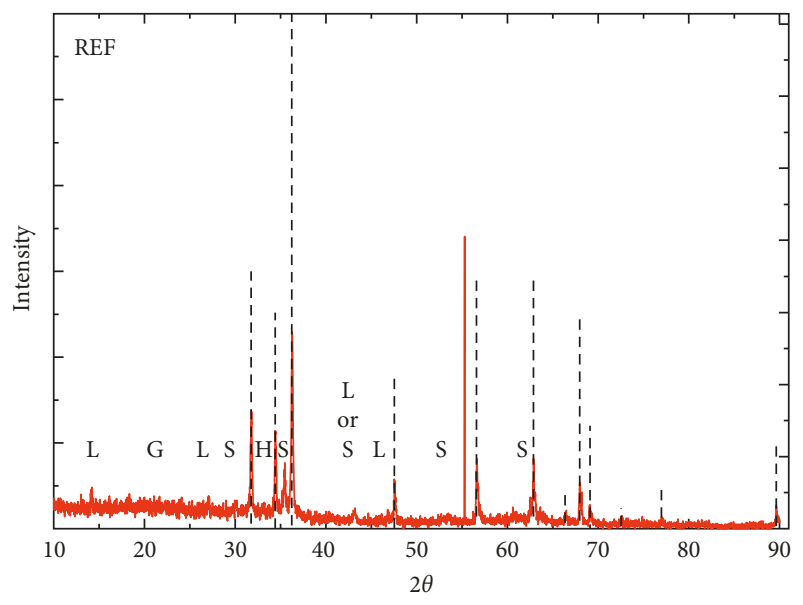

$---\mathrm{ZnO}$

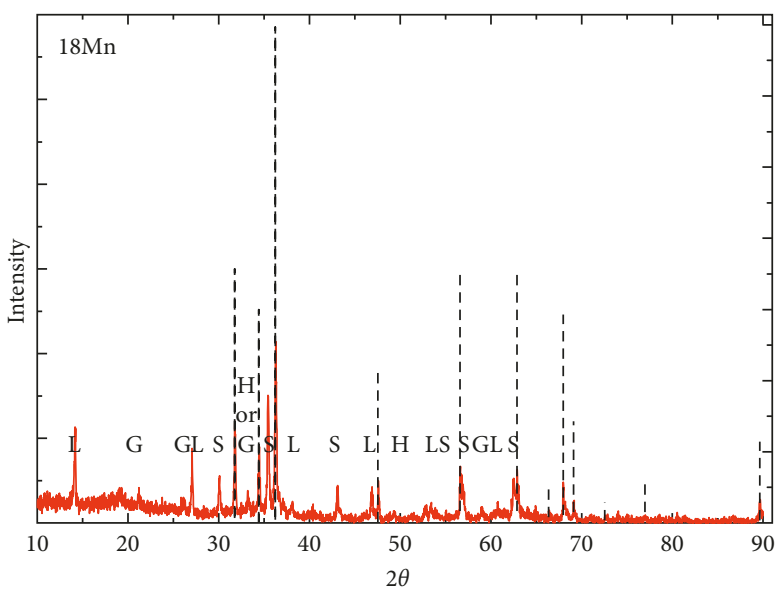

$---\mathrm{ZnO}$

(b)

(a)

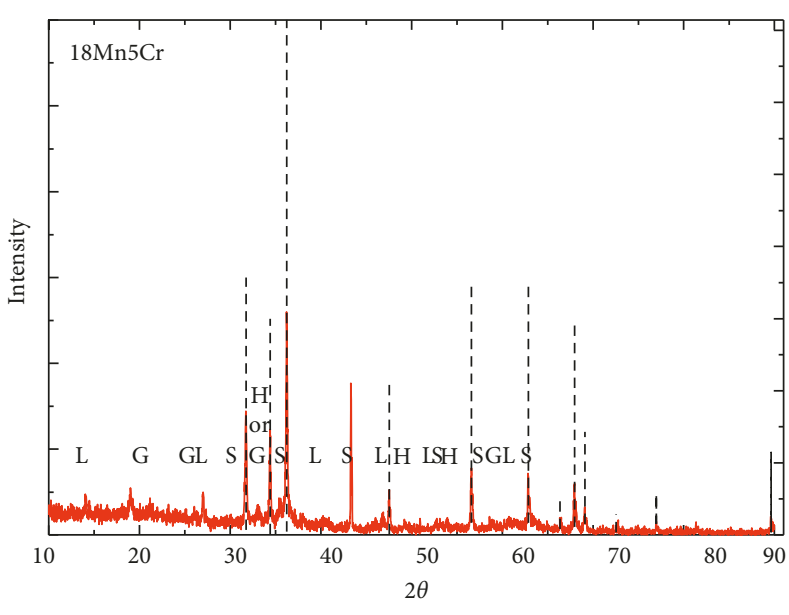

$---\mathrm{ZnO}$

(c)

FIGURE 3: XRD patterns of the nonadherent rust (NAR) formed on (a) REF, (b) $18 \mathrm{Mn}$, and (c) $18 \mathrm{Mn} 5 \mathrm{Cr}$ for 56 days in $3.5 \% \mathrm{NaCl}$ solution at $60^{\circ} \mathrm{C}$, where $\mathrm{G}, \mathrm{L}, \mathrm{S}$, and $\mathrm{H}$ represent goethite, lepidocrocite, magnetite (or maghemite), and hematite, respectively.

rust. Therefore, the relationship between the alloying element and rust will be discussed based on the results of the rust analysis in Sections 3.3 and 3.4.

\subsection{Effect of Alloying Elements on Cathodic Polarization} Curve. Cathodic polarization tests were also conducted in order to confirm the effectiveness of the Tafel extrapolation method in evaluating the corrosion rate. Figure 2(b) shows that cathodic current densities for all the alloys increased with immersion unexpectedly. The increase of the cathodic current density resulted from the involvement of electrochemical reaction of rust $[4,42,43]$. However, the effects of electrochemical reduction of rust on both the Tafel slope and the corrosion rate induced from Tafel extrapolation were different among both alloys and immersion periods. On the 
TABLE 5: Results on XRD qualitative analysis of nonadherent rusts (NARs) formed for 56-day exposure in $3.5 \% \mathrm{NaCl}$ solution according to the internal standard method.

\begin{tabular}{|c|c|c|c|c|c|c|}
\hline \multirow{2}{*}{ Alloys } & \multicolumn{6}{|c|}{ Phase fraction (wt.\%) } \\
\hline & Goethite & Akaganeite & Lepidocrocite & Spinel oxide* & Hematite & Total \\
\hline REF & 0.2 & 0.0 & 10.8 & 4.7 & 7.4 & 21.1 \\
\hline $18 \mathrm{Mn}$ & 1.0 & 0.0 & 9.9 & 5.3 & 4.0 & 20.2 \\
\hline $18 \mathrm{Mn} 5 \mathrm{Cr}$ & 4.2 & 0.0 & 10.3 & 0.3 & 4.6 & 19.4 \\
\hline
\end{tabular}

${ }^{*}$ Magnetite or maghemite.

other hand, the electrochemical reduction of rust formed on $18 \mathrm{Mn} 5 \mathrm{Cr}$ for 56 -day period was not involved in the potential range between the corrosion potential and the potential by $100 \mathrm{mV}$ lower than the corrosion potential. It decreased both the corrosion rate and the Tafel slope in Table 4 as a typical cathodic behavior of steel with a protective rust layer. Meanwhile, the electrochemical reduction of rust formed on $18 \mathrm{Mn}$ for 56 -day period was involved in the entire range of potential between the corrosion potential and the potential by $100 \mathrm{mV}$ lower than the corrosion potential. It increased the cathodic current in Figure 2(b) pretending to increase the corrosion rate in Table 4 unlike in Figure 1. The electrochemical reduction of rust formed on REF for 56-day period was involved near a potential by $100 \mathrm{mV}$ lower than the corrosion potential, increasing the Tafel slope with the decreased corrosion rate in Table 4 though the cathodic current increased in Figure 2(b). Hence, the extrapolation method could not provide reliable data for the instantaneous corrosion rate of steels with various alloying elements and immersion periods.

\subsection{Analysis of Nonadherent Rust by XRD and Raman} Spectroscopy. Figure 3 shows the XRD spectra of the NARs from the alloys immersed for 56 days. The NARs consisted of goethite (JCPDS no. 29-0713), lepidocrocite (JCPDS no. 441415), spinel oxide (magnetite (JCPDS no. 39-1346) or maghemite (JCPDS 19-0629)), and hematite (JCPDS no. 330664). The NAR constituents were independent of alloying elements. Table 5 shows the quantitative analysis summaries of the NARs. The concentration of each iron oxide in the NARs depended on the alloying element. Compared with no alloying element, the addition of chromium as an alloying element increased the concentration of goethite, which is beneficial to the corrosion resistance of steels [15-18], but decreased the concentrations of hematite as well as spinel oxide which negatively affects the corrosion resistance of steels [15-18]. The addition of manganese as an alloying element also slightly increased the concentrations of goethite but not as much as that by chromium. These results are consistent with the effects of alloying elements on corrosion resistance described in Section 3.1 and 3.2. Additionally, the total concentration of iron oxides in Table 5 was far from $100 \%$. This difference was caused by either the large amounts of amorphous rust presented during the initial period $[28,44-46]$ or detection limits of XRD and Raman spectroscopy on fine grains [44-46].

Figure 4 shows the Raman spectra of the NARs formed on the alloys. The Raman spectra of the NARs sampled from REF demonstrate the presence of goethite, lepidocrocite,

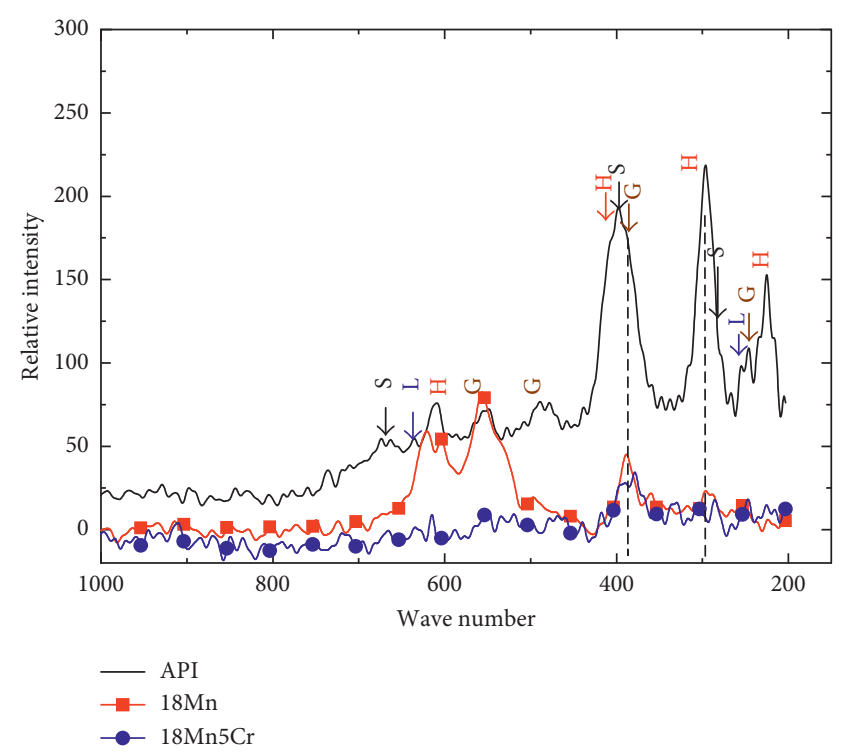

FIGURE 4: Raman spectra of the nonadherent rust (NAR) formed on REF, $18 \mathrm{Mn}$, and $18 \mathrm{Mn} 5 \mathrm{Cr}$ for 56 days in $3.5 \% \mathrm{NaCl}$ solution at $60^{\circ} \mathrm{C}$, where $\mathrm{G}, \mathrm{L}, \mathrm{S}$, and $\mathrm{H}$ represent goethite, lepidocrocite, magnetite (or maghemite), and hematite, respectively. S: spinel oxide, $\mathrm{H}: \alpha-\mathrm{Fe}_{2} \mathrm{O}_{3}, \mathrm{G}: \alpha-\mathrm{FeOOH}, \mathrm{L}: \gamma$-FeOOH.

hematite, and magnetite which was confirmed by the absence of the broadband at $710 \mathrm{~cm}^{-1}$ [47]. The Raman spectra of the NAR formed on the $18 \mathrm{Mn}$ mainly presented bands at $554,390,621,598$, and $500 \mathrm{~cm}^{-1}$, where the first two bands correspond to goethite and the last three bands possibly correspond to $\mathrm{Mn}$-rich bixbyite $\left((\mathrm{Mn}, \mathrm{Fe})_{2} \mathrm{O}_{3}\right)$ [48]. In addition to major bands, bands for magnetite and hematite were detected with low intensity in the Raman spectra. The low density of hematite is due to the fact that manganese promotes the formation of Mn-rich iron bixbyite instead of the formation of hematite in NARs. In addition, no detection of lepidocrocite in the Raman spectrum from the $18 \mathrm{Mn}$ is possible due to low sensitivity of lepidocrocite in Raman spectroscopy, which was also observed in the NARs sampled from REF in Figure 4, corresponding to $10.8 \%$ of lepidocrocite as listed in Table 5. The Raman spectrum of the NARs formed on the $18 \mathrm{Mn} 5 \mathrm{Cr}$ was also similar to that from the NARs of the $18 \mathrm{Mn}$, with an exception of the absence of bands from Mn-rich bixbyite. The absence of Mn-rich iron oxide in the NARs from the $18 \mathrm{Mn} 5 \mathrm{Cr}$ is due to the stabilization of oxyhydroxides by chromium as listed in Table 5 .

XRD and Raman spectrum analysis did not find maghemite and akaganeite in the NARs in comparison to past experiments 
and previous studies that were performed at room temperature $[18,49]$. The formation of hematite or Mn-rich iron oxide from dihydroxylation of oxyhydroxide via maghemite [22] may have resulted from conducting the experiment at a higher temperature than at room temperature, increasing the rate of the reaction for formation of hematite. The higher testing temperature may also have caused transformation of akaganeite to stable oxyhydroxide or hematite [29].

Therefore, the NARs from all the alloys, independent of alloying elements, consisted of goethite, lepidocrocite, magnetite, and hematite. However, the concentration of constituents in the NARs depended on alloying elements, affecting corrosion resistance of the alloys.

3.4. Analysis of Adherent Rust by XRD and TEM. Figure 5 shows the spectra of rusts sampled from the alloys immersed for 56 days. Two measurement methods for the XRD spectrum both demonstrate the presence of spinel oxide in the ARs despite the difference in their intensities. Afterwards, the spinel oxide was identified with magnetite from the results of EELS analysis as shown in Table 6 and (3).

For more detailed examination, the ARs were used for TEM analysis with EDS, SAED, and EELS. Their results are shown in Figures 6-8. Figure 6(a) shows that the ARs sampled from the REF consisted of white and gray regions. Both regions contained iron and oxygen, but the white region had lower concentration of iron than the gray region as shown in Figure 6(b). In addition, the EELS analysis as shown in Table 6 and Figure 9 demonstrated higher concentration of ferric iron in the white region which formed along the alloy/rust interface and across the AR in a line form such as a grain boundary. To satisfy the EDS and EELS analysis results, the oxidation state of iron is higher and the atomic ratio of iron to oxygen is lower in the white region. The Pt peak observed from EDS analysis came from platinum coated on the sample surface before FIB cutting. The Pt peak was no more mentioned hereafter. The SAED analysis further supports the findings, where the white region near the metal/rust interface mainly consists of feroxyhyte (JCPDS no. 18-0087) and magnetite as shown in Figure 6(c), while the gray region is identified with magnetite as shown in Figure 6(d). Hence, the distribution of the oxidation state of iron in the ARs from the REF indicates that the penetration of oxygen through a fast transport pathway controls the corrosion process of the REF.

Figures 7(a) and 7(b) provide TEM images of the ARs on the $18 \mathrm{Mn}$ and the EDS analyses, respectively. Contrast in the rust as shown in Figure 7(a) is relatively constant compared to that in Figure 6(a), and the concentration of iron, manganese, and oxygen remained constant as in the REF except for the presence of metallic components shown as point 2 in Figure 7(a). The latter is near the AR/NAR interface. In addition, the ratio shown in Table 6 and Figure 9 is almost constant, regardless of the area, and was lower than the ratio detected from the ARs from the REF. This outcome indicates that the oxidation state of iron in the ARs from the $18 \mathrm{Mn}$ is lower than that in the ARs from the REF [41]. The lower oxidation state of iron in the ARs was confirmed by the
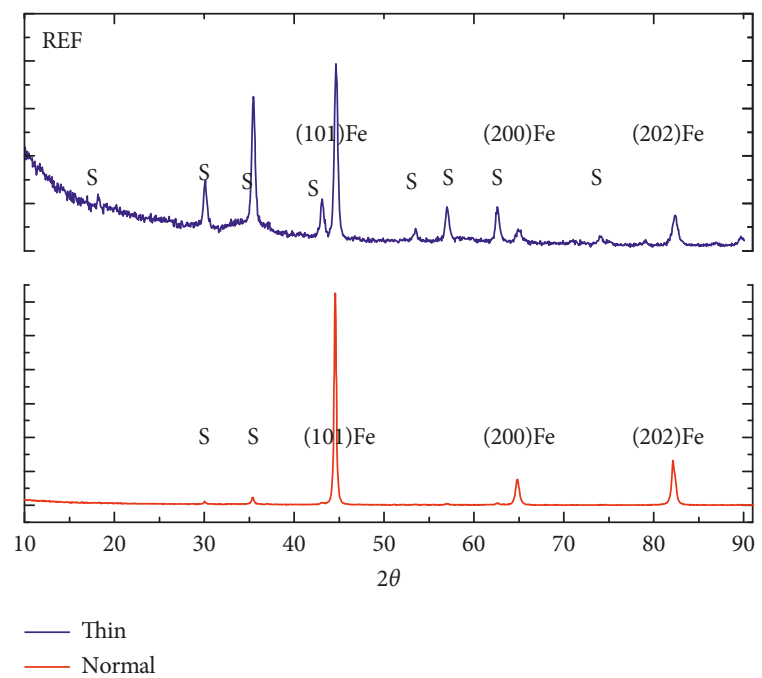

(a)
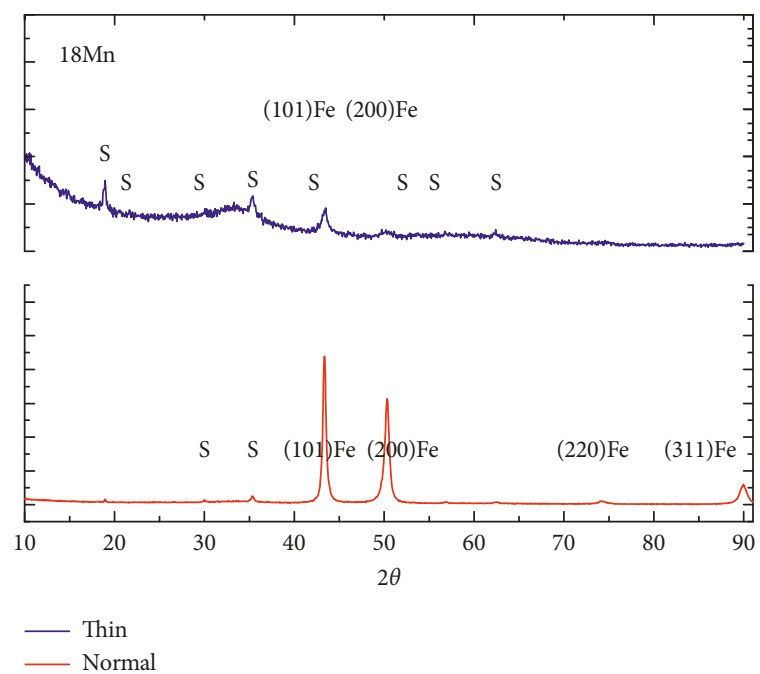

(b)
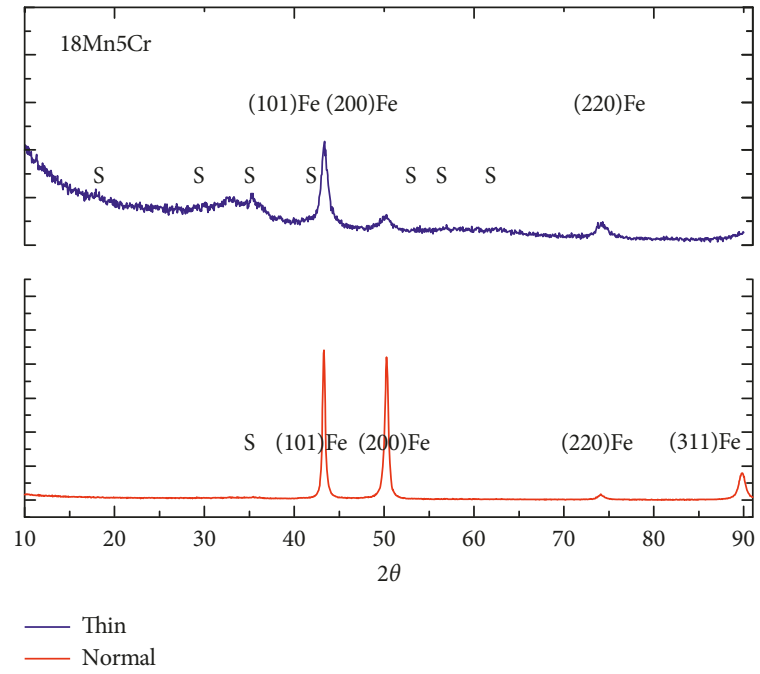

(c)

FIGURE 5: XRD patterns of the adherent rust (AR) formed on (a) REF, (b) $18 \mathrm{Mn}$, and (c) $18 \mathrm{Mn} 5 \mathrm{Cr}$ for 56 days in $3.5 \%$ $\mathrm{NaCl}$ solution at $60^{\circ} \mathrm{C}$, where $\mathrm{S}$ represents magnetite (or maghemite). 
TABLE 6: Summary on the integral intensity ratio of $\mathrm{Fe}_{3}$ edge peak to $\mathrm{Fe}_{2}$ edge peak depending on various positions among rust formed on $\mathrm{REF}, 18 \mathrm{Mn}$, and $18 \mathrm{Mn} 5 \mathrm{Cr}$ for 56 days in $3.5 \% \mathrm{NaCl}$ solution at $60^{\circ} \mathrm{C}$.

\begin{tabular}{lccc}
\hline Alloy & Distance from metal/rust interface $(\mu \mathrm{m})$ & Points in Figures 6-8 & $I\left(\mathrm{Fe} \mathrm{L}_{3}\right) / I\left(\mathrm{Fe} \mathrm{L}_{2}\right)$ \\
\hline & 0.133 & e1 in Figure 6(a) & 6.01 \\
& 0.333 & e2 in Figure 6(a) & 5.50 \\
$\mathrm{REF}$ & 0.320 & e3 in Figure 6(a) & 6.26 \\
& 0.400 & e4 in Figure 6(a) & 6.82 \\
& 0.827 & e5 in Figure 6(a) & 7.97 \\
& 0.880 & e6 in Figure 6(a) & 6.37 \\
$18 \mathrm{Mn}$ & 1.100 & e7 in Figure 6(a) & 5.65 \\
& 0.165 & e1 in Figure 7(a) & 5.46 \\
$18 \mathrm{Mn} 5 \mathrm{Cr}$ & 0.235 & e2 in Figure 7(a) & 5.57 \\
& 0.424 & e3 in Figure 7(a) & e1 in Figure 8(a) \\
\hline
\end{tabular}

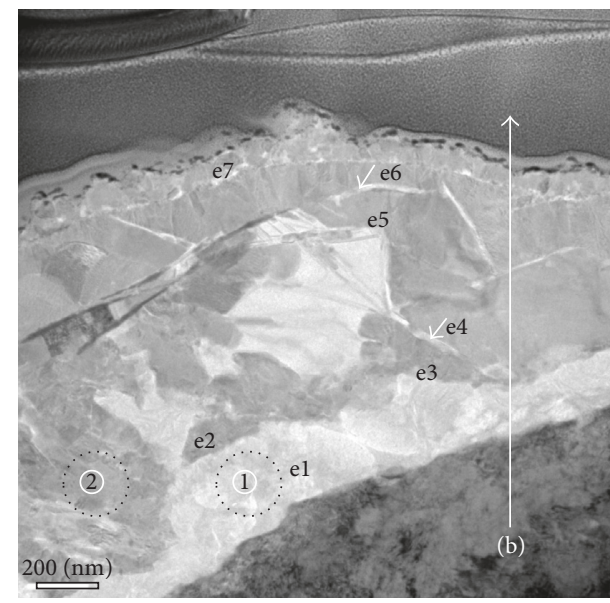

(a)

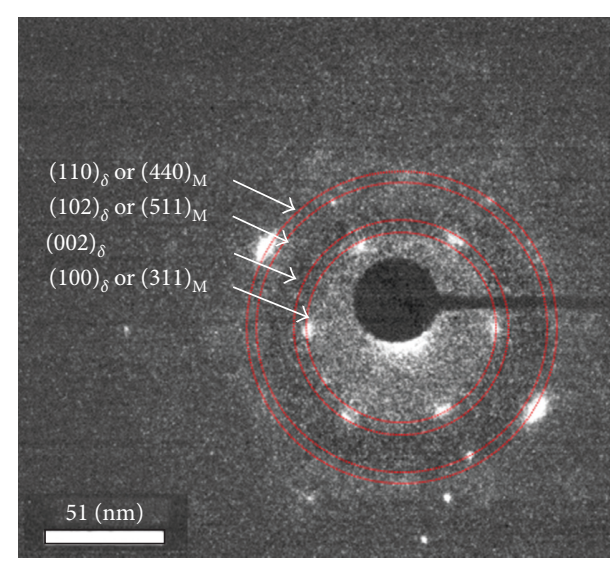

(c)

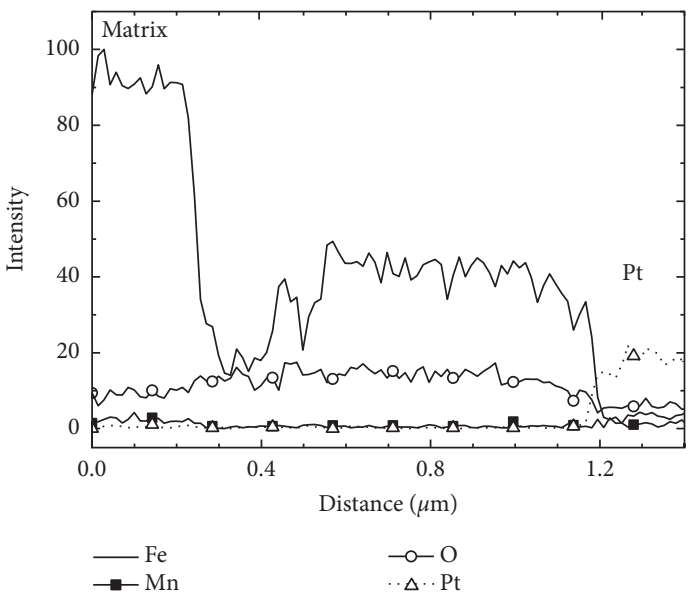

(b)

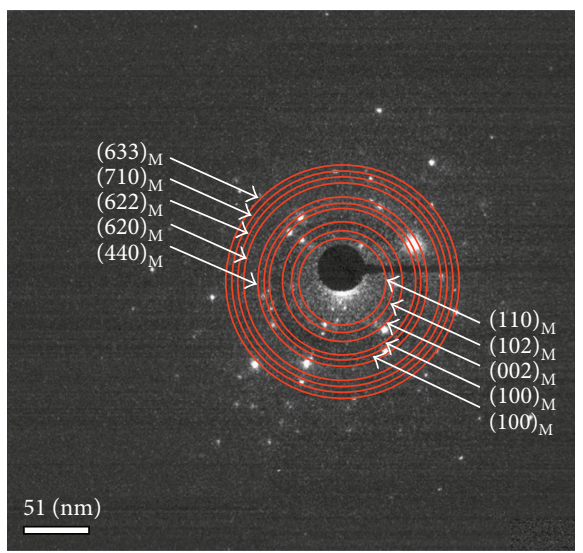

(d)

Figure 6: Cross-sectional TEM image (a), EDS line profile (b), and SAEDs (c-d) of regions 1 and 2 in rust formed during 56-day immersion of $\mathrm{REF}$ in $3.5 \% \mathrm{NaCl}$ solution at $60^{\circ} \mathrm{C}$, where the subscripts $\delta$ and $\mathrm{M}$ indicate feroxyhyte and magnetite, respectively.

identification of the ARs as magnetite from SAED analysis as shown in Figure 7(d). Furthermore, more TEM spots with an interplanar spacing of $\{\mathrm{hkl}\}\left(d_{\mathrm{hkl}}\right)$ in Figure $7(\mathrm{~d})$ than in Figure $6(c)$ or $6 \mathrm{~d}$ indicate that the AR grain sizes on the
$18 \mathrm{Mn}$ is smaller than those on the REF when the aperture sizes marked as the dot circles as shown are compared in Figures 6(a) and 7(a). From the abovementioned results, manganese as an alloying element aided the uniform 


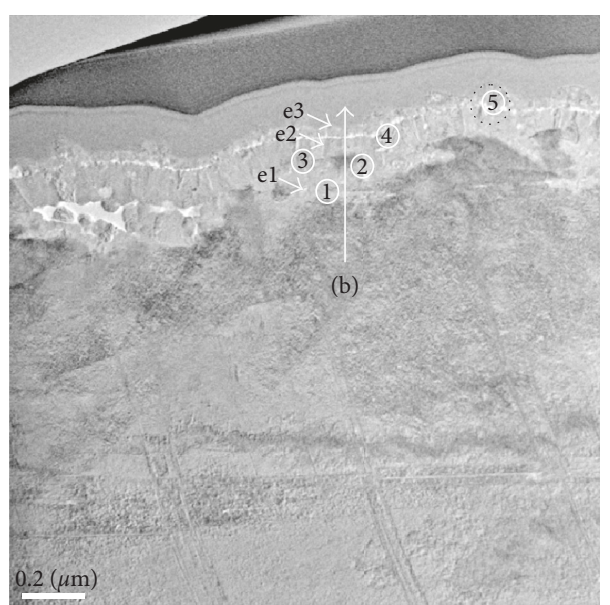

(a)

\begin{tabular}{llcc}
\hline $\begin{array}{l}\text { Position } \\
\text { in (a) }\end{array}$ & $\mathrm{Fe}$ & Chemical composition (wt\%) \\
\hline (1) & 66.8 & 13.4 & $\mathrm{O}$ \\
(2) & 76.0 & 18.4 & 19.8 \\
(3) & 76.2 & 4.63 & 5.6 \\
(4) & 71.6 & 3.43 & 19.2 \\
\hline
\end{tabular}

(c)

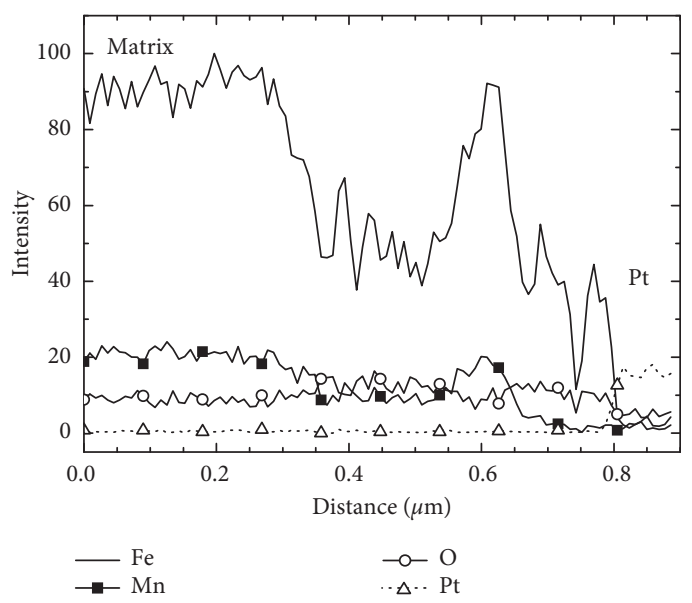

(b)

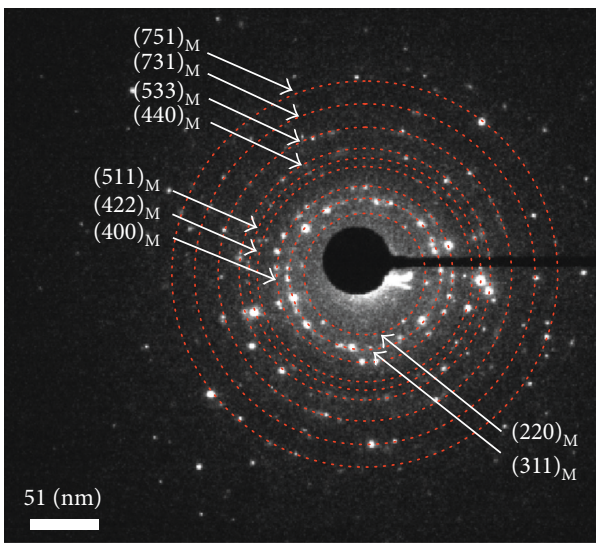

(d)

FIGURE 7: Cross-sectional TEM image (a), EDS line profile (b), EDS quantitative analysis of selected points 1, 2, 3, and 4 (c), and SAED (d) of region 5 in rust formed during 56 -day immersion of $18 \mathrm{Mn}$ in $3.5 \% \mathrm{NaCl}$ solution at $60^{\circ} \mathrm{C}$, where subscript $\mathrm{M}$ indicates magnetite.

formation of rust and the refinement of the grain sizes of ARs, allowing oxygen to penetrate into ARs, retarding the formation of ferric ion, and ultimately increasing the corrosion resistance of the $18 \mathrm{Mn}$.

Figure 8(a) shows a TEM image of the ARs from the $18 \mathrm{Mn} 5 \mathrm{Cr}$. Similar to Figure $7(\mathrm{a})$, the image was almost constant contrast, whereas the EDS intensities in Figure 8(b) were almost constant, unlike in Figure $7(\mathrm{~b})$, except the decreased intensity of iron from a distance longer than $0.2 \mu \mathrm{m}$ away from the alloy/AR interface. As shown in Figure 8(c), those outcomes caused the enrichment of manganese and chromium. Despite the enrichment of chromium and manganese, however, the ratio shown in Table 6 and Figure 9 is almost as constant as that of AR formed on the $18 \mathrm{Mn}$, indicating that the oxidation state of iron in the AR from the $18 \mathrm{Cr} 5 \mathrm{Mn}$ is the same as that of the AR from the $18 \mathrm{Mn}$. Figures $8(\mathrm{~d})$ and $8(\mathrm{e})$ demonstrate that the ARs from the $18 \mathrm{Cr} 5 \mathrm{Mn}$ were mainly magnetite and have the finest grain based on the comparison of aperture sizes in Figures 6(a), 7(a), and 8(a). Here, chromium and manganese enrichments near the AR/NAR interface may be explained with the substitution of ferric ion and ferrous ion by chromium(III) and manganese(II) in magnetite, respectively.
As both chromium and manganese retard the formation of magnetite [34] and aid the formation of oxyhydroxide in the NARs, iron ions may have diffused out and promoted the enrichment. Therefore, chromium aids the uniform rust formation and the refinement of the grain size in ARs and the formation of enriched ( $\mathrm{Cr}, \mathrm{Mn}$ ) oxyhydroxide in the NARs, hindering effective oxygen penetration into ARs and increasing the corrosion resistance of $18 \mathrm{Mn} 5 \mathrm{Cr}$.

\section{Discussion}

Since the corrosion resistance of steels was controlled by the penetration of oxygen into rust, the following modification of rust properties by chromium and manganese improved the corrosion resistance as sketched in Figure 10. Compared to the rust on the REF, both chromium and manganese accelerate the formation of goethite in NARs and finegrained magnetite in ARs, though the chromium is more effective than manganese as shown in Figures 10(b) and 10 (c). The higher effectiveness of chromium on corrosion resistance of steels is because both the formation rate and refinement of goethite are enhanced in NARs $[4,36,50]$ as well as AR grain sizes are more refined [36]. The higher 


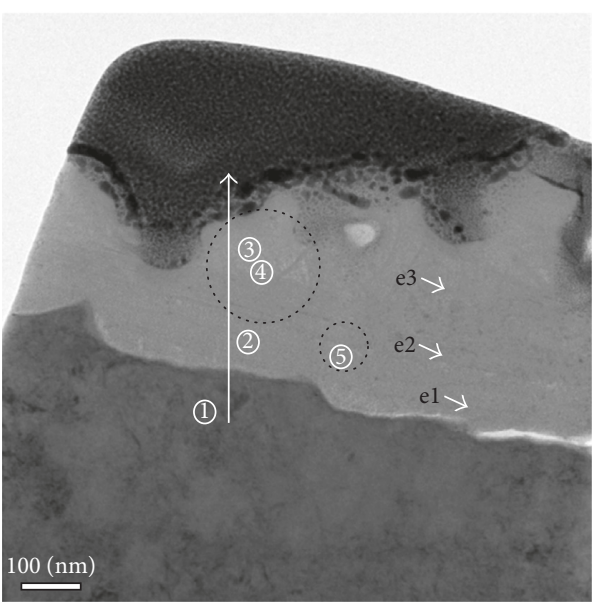

(a)

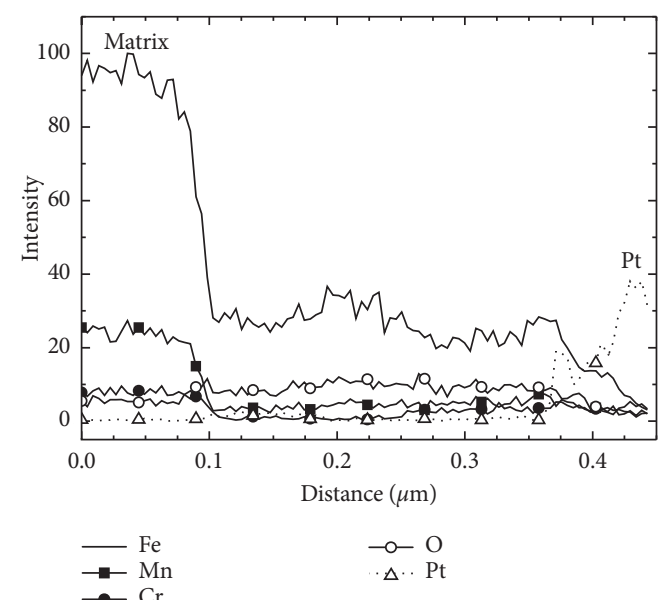

(b)

\begin{tabular}{lcccc}
\hline Position & \multicolumn{4}{c}{ Chemical composition (wt\%) } \\
in (a) & $\mathrm{Fe}$ & $\mathrm{Mn}$ & $\mathrm{Cr}$ & $\mathrm{O}$ \\
\hline (1) & 73.9 & 18.6 & 5.3 & 2.2 \\
(2) & 63.1 & 8.3 & 1.1 & 25.4 \\
(3) & 50.6 & 12.8 & 5.8 & 30.8 \\
\hline
\end{tabular}

(c)

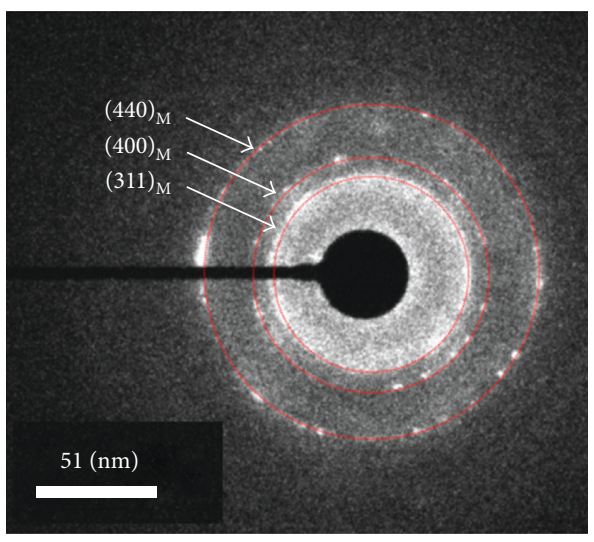

(d)

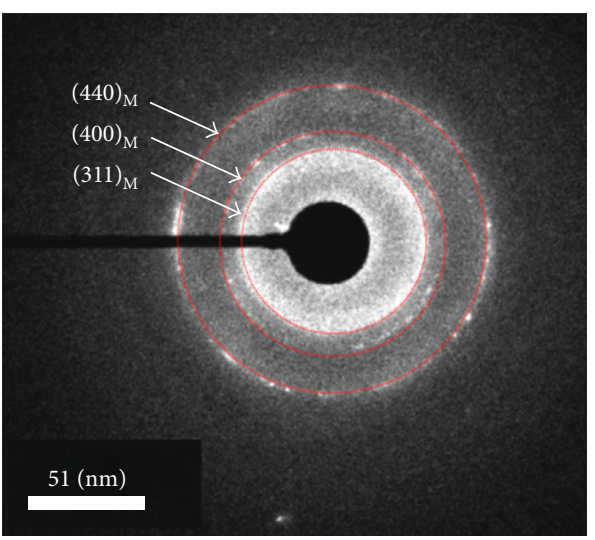

(e)

Figure 8: Cross-sectional TEM image (a), EDS line profile (b), EDS quantitative analysis of selected points 1, 2, and 3 (c), and SAEDs (d-e) of regions 4 and 5 in rust formed during 56 -day immersion of $18 \mathrm{Mn} 5 \mathrm{Cr}$ in $3.5 \% \mathrm{NaCl}$ solution at $60^{\circ} \mathrm{C}$, where subscript $\mathrm{M}$ indicates magnetite.

effectiveness of chromium on the formation of goethite has been explained with both facilitated incorporation of chromium into goethite as chromium is more soluble than manganese [51, 52] and faster precipitation of chromium (III) ion to $\mathrm{Cr}(\mathrm{OH})_{3}$ than ferrous ion during the oxidation of the ferrous solutions [50]. The fast pathway where oxygen is transported across NARs is provided by pores or their surface area. The porosity of rust is affected by phase transformation of rust, interparticle spacing, type of iron oxide and substituting ions into the oxide, grain size, and crystal structure [24]. However, a higher porosity does not always result in a higher transport rate due to mobility and the size of the pore [24]. For example, more refined grain provides a low transport rate of oxygen despite its high surface area. Accordingly, the study on mobility as well as the size of the pore remains for future work. Therefore, the lower transport rate of oxygen across rust on the alloy steels
(18Mn, 18Mn5Cr) was explained with the more refined grain size of goethite in the NARs without further mentioning porosity.

Unlike previous studies $[15,16,18]$, which state that magnetite is related to a decrease in corrosion resistance of steel, the ARs formed on the alloy steels with higher corrosion resistances contained fine magnetite as a main component. The discrepancy is due to the difference in the location of rust from the alloy/rust interface. Magnetite is formed from the following reactions: slow oxidation of ferrous hydroxide by way of GR, incorporation of ferrous ion into oxyhydroxide [7], or dissolution-precipitation process - the early precipitated oxyhydroxide reacts with the dissolved ferrous hydroxide to produce magnetite $[29,53]$. On the alloy steels, magnetite exists as a main oxide in the inner layer of ARs because of the difficulty in transporting oxygen through both NARs and ARs. However, 


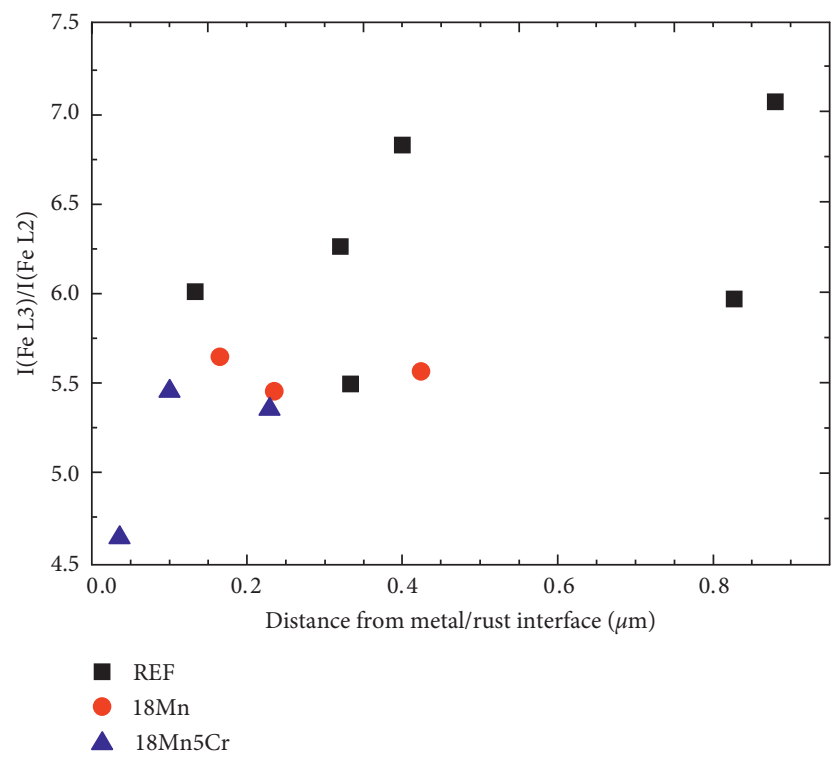

FIGURE 9: Integral intensity ratio of Fe L3 edge peak to Fe L2 edge peak depending on the distance from the metallic surface of REF, 18Mn, and $18 \mathrm{Mn} 5 \mathrm{Cr}$ presented in Table 6.

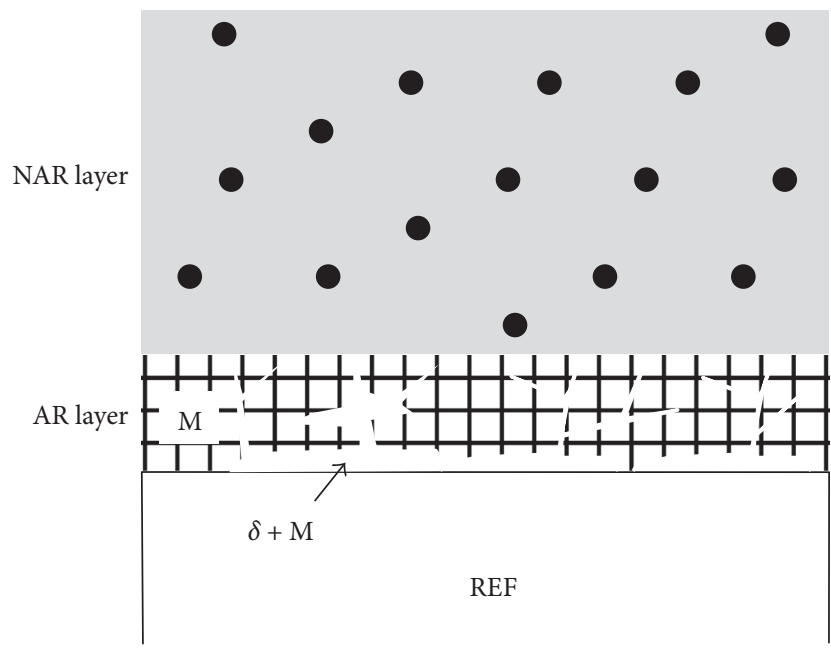

(a)

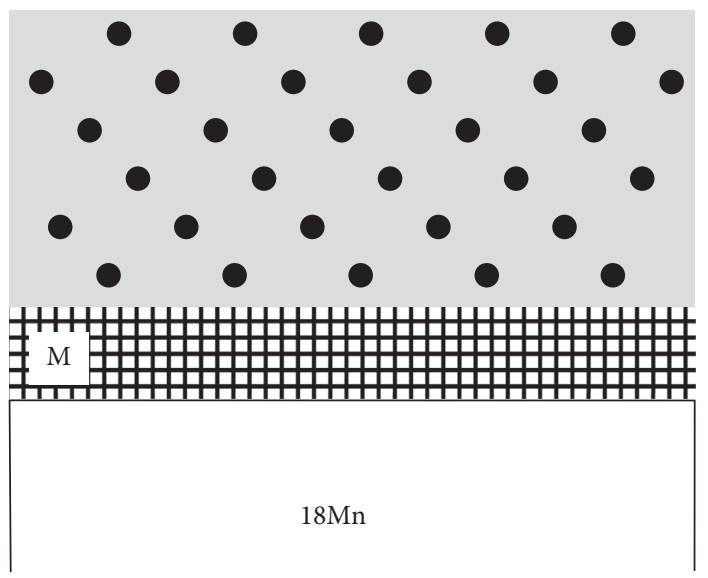

(b)

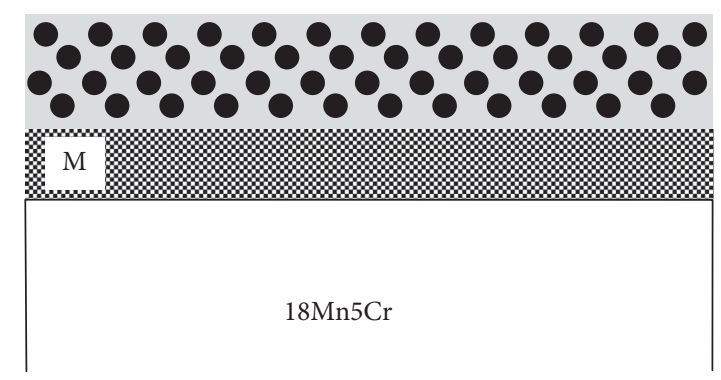

(c)

Figure 10: Schematic diagrams of rust layers formed on REF (a), $18 \mathrm{Mn}(\mathrm{b})$, and $18 \mathrm{Mn} 5 \mathrm{Cr}$ (c) in $3.5 \% \mathrm{NaCl}$ solution for 56 days at $60^{\circ} \mathrm{C}$, where solid circle, $M$, and $\delta$ indicate goethite, magnetite, and feroxyhyte, respectively. 
the formation of the less-protective rust layer like the NAR and the AR on the REF provides a fast pathway for oxygen penetration and aids oxyhydroxide formation [28], decreasing the concentration of magnetite. Hence, the higher concentration of magnetite in the AR indicates the higher resistance of the alloy on which the AR is formed unlike the expectation according to (1).

\section{Conclusions}

From the evaluation of corrosion resistance of REF, $18 \mathrm{Mn}$, and $18 \mathrm{Mn} 5 \mathrm{Cr}$ in $60^{\circ} \mathrm{C} 3.5 \% \mathrm{NaCl}$ solution and the analysis of the AR and NAR by XRD, Raman spectroscopy, TEM-EDS, TEM-SADP, and TEM-EELS, the corrosion process and the effects of chromium and manganese on the process are described in detail in the following:

(1) In $60^{\circ} \mathrm{C} \mathrm{NaCl}$ solution, the corrosion processes of all the alloys were controlled by the oxygen transport through the rust layer. The weight loss behavior conformed to a typical parabolic law; the oxidation state of iron in rust was higher along the fast pathway but it was not proportional to the longer distance from the alloy/AR interface.

(2) Both chromium and manganese as alloying elements not only increased the amounts of goethite in NARs but also refined the AR grain size. In addition, the alloying elements decreased the concentration ratio of ferric ion to ferrous ion in ARs indicating the difficulty in oxygen penetration.

(3) The higher corrosion resistance of $18 \mathrm{Mn} 5 \mathrm{Cr}$ resulted from the effectiveness of chromium in refinements of AR grains and increased amounts of goethite in NARs.

In addition, the Tafel extrapolation method does not provide reliable data for the instantaneous corrosion rate of steels with various alloying elements and immersion periods because the electrochemical reduction rate of rust depends on its constituents as well as corrosion potentials which are affected by the alloying element.

\section{Conflicts of Interest}

The author declares that there are no conflicts of interest regarding the publication of this paper.

\section{Acknowledgments}

The authors gratefully acknowledge the financial supports from POSCO.

\section{References}

[1] H. N. Han, C.-S. Oh, G. Kim, and O. Kwon, "Design method for TRIP-aided multiphase steel based on a microstructurebased modelling for transformation-induced plasticity and mechanically induced martensitic transformation," Materials
Science and Engineering: A, vol. 499, no. 1-2, pp. 462-468, 2009.

[2] O. Soderberg, "Corrosion behaviour of Fe-Mn-Si based shape memory steels trained by cold rolling," Materials Science and Engineering: A, vol. 273-275, pp. 543-548, 1999.

[3] M. B. Kannan, R. K. S. Raman, and S. Khoddam, "Comparative studies on the corrosion properties of a Fe-Mn-Al-Si steel and an interstitial-free steel," Corrosion Science, vol. 50, no. 10, pp. 2879-2884, 2008.

[4] Y. Hyun and H. Kim, "Effects of alloying elements (Cr, Mn) on corrosion properties of carbon steel in synthetic seawater," Korean Journal of Metals and Materials, vol. 54, pp. 68-78, 2016.

[5] Y. Hyun and H. Kim, "Effects of alloying elements on the corrosion properties of high strength steel in a sour environment," Korean Journal of Metals and Materials, vol. 54, no. 12, pp. 885-892, 2016.

[6] Y. S. Zhang and X. M. Zhu, "Electrochemical polarization and passive film analysis of austenitic $\mathrm{Fe}-\mathrm{Mn}-\mathrm{Al}$ steels in aqueous solutions," Corrosion Science, vol. 41, no. 9, pp. 1817-1833, 1998.

[7] X. M. Zhu and Y. S. Zhang, "Investigation of the electrochemical corrosion behavior and passive film for Fe-Mn, Fe$\mathrm{Mn}-\mathrm{Al}$, and Fe-Mn-Al-Cr alloys in aqueous solutions," Corrosion Science, vol. 54, no. 1, pp. 3-12, 1998.

[8] P. H. Refait, M. Abdelmoula, and J. M. R. Genin, "Mechanisms of formation and structure of green rust one in aqueous corrosion of iron in the presence of chloride ions," Corrosion Science, vol. 40, no. 9, pp. 1547-1560, 1998.

[9] G. Mcadam and D. J. Young, "Mechanisms of the simultaneous sulfidation and oxidation of Fe-Mn alloys," Corrosion Science, vol. 38, no. 2, pp. 247-266, 1996.

[10] K. Asami and M. Kikuchi, "Characterization of rust layers on weathering steels air-exposed for a long period," Materials Transactions, vol. 43, no. 11, pp. 2812-2825, 2002.

[11] J. Rawers, "Oxidation characteristics of $\mathrm{Fe}-18 \mathrm{Cr}-18 \mathrm{Mn}$ stainless steel alloys," Oxidation of Metals, vol. 74, no. 3-4, pp. 167-178, 2010.

[12] D. Neff, P. Dillmann, L. Bellot-Gurlet, and G. Beranger, "Corrosion of iron archaeological artefacts in soil: characterisation of the corrosion system," Corrosion Science, vol. 47, no. 2, pp. 515-535, 2005.

[13] R. E. Melchers, "Effect of small compositional changes on marine immersion corrosion of low alloy steels," Corrosion Science, vol. 46, no. 7, pp. 1669-1691, 2004.

[14] R. E. Melchers, "Long-term corrosion of cast irons and steel in marine and atmospheric environments," Corrosion Science, vol. 68, pp. 186-194, 2013.

[15] S. Hara, T. Kamimura, H. Miyuki, and M. Yamashita, "Taxonomy for protective ability of rust layer using its composition formed on weathering steel bridge," Corrosion Science, vol. 49, no. 3, pp. 1131-1142, 2007.

[16] T. Kamimura, S. Hara, H. Miyuki, M. Yamashita, and H. Uchida, "Composition and protective ability of rust layer formed on weathering steel exposed to various environments," Corrosion Science, vol. 48, no. 9, pp. 2799-2812, 2006.

[17] A. L. Morales, D. Cartagena, J. L. Rendon, and A. Valencia, "The relation between corrosion rate and corrosion products from low carbon steel," Physica Status Solidi (B), vol. 220, no. 1, pp. 351-356, 2000.

[18] F. R. Perez, C. A. Barrero, A. R. Hight Walker, K. E. Garcia, and K. Nomura, "Effects of chloride concentration, immersion time and steel composition on the spinel phase formation," Materials Chemistry and Physics, vol. 117, no. 1, pp. 214-223, 2009. 
[19] M. Yamashita, H. Miyuki, Y. Matsuda, H. Nagano, and T. Misawa, "The long term growth of the protective rust layer formed on weathering steel by atmospheric corrosion during a quarter of a century," Corrosion Science, vol. 36, pp. 283299, 1994.

[20] P. H. Bauer, J. M. Genin, and D. Rezel, "Mössbauer effect evidence of chlorine environments in ferric oxyhydroxides from iron corrosion in chlorinated aqueous solution," $\mathrm{Hy}$ perfine Interactions, vol. 28, no. 1-4, pp. 757-760, 1986.

[21] R. A. Robie, B. S. Hemingway, and J. R. Fischer, Thermodynamic properties of minerals and related substances at 298.15 $K$ and 1 bar (105 pascals) pressure and high temperatures, Washington, DC, USA, 1978.

[22] R. M. Cornell and U. Schwertmann, The Iron Oxides, p. 181, VCH Publishers, New York, NY, USA, 1996.

[23] S. J. Oh, D. C. Cook, and H. E. Townsend, "Atmospheric corrosion of different steels in marine, rural and industrial environments," Corrosion Science, vol. 41, no. 9, pp. 1687-1702, 1999.

[24] R. M. Cornell and U. Schwertmann, The Iron Oxides, pp. 98-110, VCH Publishers, New York, NY, USA, 2006.

[25] U. R. Evans and C. A. J. Taylor, "Mechanism of atmospheric rusting," Corrosion Science, vol. 12, no. 3, pp. 227-246, 1972.

[26] J. T. Keiser, C. W. Brown, and R. H. Heidersbach, "The electrochemical reduction of rust films on weathering steel surfaces," Journal of the Electrochemical Society, vol. 129, no. 12 , pp. 2686-2689.

[27] J. P. Jolivet, E. Tronc, and C. R. Chaneac, "Iron oxides: from molecular clusters to solid. A nice example of chemical versatility," Comptes Rendus Geoscience, vol. 338, no. 1-7, pp. 488-497, 2006.

[28] T. Misawa, T. Kyuno, W. Suetaka, and S. Shimodaira, "The mechanism of atmospheric rusting and the effect of $\mathrm{Cu}$ and $\mathrm{P}$ on the rust formation of low alloy steels," Corrosion Science, vol. 11, no. 1, pp. 35-48, 1971.

[29] T. Ishikawa, Y. Kondo, A. Yasukawa, and K. Kandori, "Formation of magnetite in the presence of ferric oxyhydroxides," Corrosion Science, vol. 40, no. 7, pp. 1239-1251, 1998.

[30] Y. Tamaura, K. Ito, and T. Katsura, "Transformation of $\gamma$-FeO $(\mathrm{OH})$ to $\mathrm{Fe}_{3} \mathrm{O}_{4}$ by adsorption of iron(II) ion on $\gamma$ - $\mathrm{FeO}(\mathrm{OH})$," Journal of the Chemical Society, Dalton Transactions, no. 2, pp. 189-194, 1983.

[31] R. M. Cornell, "The influence of some divalent cations on the transformation of ferrihydrite to more crystalline products," Clay Minerals, vol. 23, no. 3, pp. 329-332, 1988.

[32] R. M. Cornell and R. Giovanoli, "The influence of copper on the transformation of ferrihydrite $\left(5 \mathrm{Fe}_{2} \mathrm{O}_{3} \rightarrow 9 \mathrm{H}_{2} \mathrm{O}\right)$ into crystalline products in alkaline media," Polyhedron, vol. 7, no. 5, pp. 385-391, 1988.

[33] C. A. Barrero, A. L. Morales, J. Restrepo et al., "Synthesis of magnetite in presence of $\mathrm{Cu}^{2+}$ or $\mathrm{Cr}^{3+}$," Hyperfine Interactions, vol. 134, no. 1, pp. 141-152, 2001.

[34] T. Ishikawa, M. Kumagai, A. Yasukawa, K. Kandori, T. Nakagama, and F. Yuse, "Influences of metal ions on the formation of $\gamma$ - FeOOH and magnetite rusts," Corrosion Science, vol. 44, no. 5, pp. 1073-1086, 2002.

[35] C. A. Barrero, A. L. Morales, J. Mazo-Zuluaga et al., "Synthesis and Mossbauer characterization of $\mathrm{Cu}$ and $\mathrm{Cr}$ doped magnetites," Revista de Metalurgia (Madrid), vol. 39, pp. 62-67, 2003.

[36] A. L. Morales, C. A. Barrero, F. Jaramillo, C. Arroyave, and J. M. Greneche, "Properties of goethite grown under the presence of $\mathrm{Cr}^{3+}, \mathrm{Cu}^{2+}$ and $\mathrm{Mn}^{2+}$ ions," Hyperfine Interactions, vol. 148/149, no. 1-4, pp. 135-144, 2003.
[37] D. W. Kim and H. Kim, "Effects of alloying elements on corrosion resistance of low alloyed steels in a seawater ballast tank environment," Korean Journal of Metals and Materials, vol. 48, no. 6, pp. 523-532, 2010.

[38] ASTM G 1, Standard Practice for Preparing, Cleaning, and Evaluating Corrosion Test Specimens, ASTM International, West Conshohocken, PA, USA, 2003.

[39] D. A. Jones, Principle and Prevention of Corrosion, PrenticeHall, New Jersey, NY, USA, 2nd edition, 1996.

[40] C. Suryanarayana and M. G. Norton, X-ray Diffraction-A Practical Approach, Premium Publishing Co., New York, NY, USA, 1998.

[41] P. A. van Aken, B. Liebscher, and V. J. Styrsa, "Quantitative determination of iron oxidation states in minerals using Fe L 2,3-edge electron energy-loss near-edge structure spectroscopy," Physics and Chemistry of Minerals, vol. 25, no. 5, pp. 323-327, 1998.

[42] A. Raman, A. Razvan, B. Kuban, K. A. Clement, and W. E. Graves, "Characteristics of the rust from weathering steels in Louisiana bridge spans," Corrosion, vol. 42, pp. 447-455, 1986.

[43] Y. Zou, J. Wang, and Y. Y. Zheng, "Electrochemical techniques for determining corrosion rate of rusted steel in seawater," Corrosion Science, vol. 53, no. 1, pp. 208-216, 2011.

[44] M. Yamashita, H. Miyuki, H. Nagano, and T. Misawa, "Stabilizing process of rust layer formed on weathering steels by atmospheric corrosion for a long period," Zairyo-toKankyo, vol. 43, no. 1, pp. 26-32, 1994.

[45] M. Yamashita, H. Nagano, T. Misawa, and H. E. Townsend, "Structure of protective rust layers formed on weathering steels by long-term exposure in the industrial atmospheres of Japan and North America," ISIJ International, vol. 38, no. 3, pp. 285-290, 1998.

[46] M. Yamashita and T. Misawa, "Recent progress in the study of protective rust-layer formation on weathering steel," in Proceedings of NACE 53rd Annual Conference (Corrosion 98), San Diego, CA, USA, March 1998.

[47] S. J. Oh, D. C. Cook, and T. E. Townsend, "Characterization of iron oxides commonly formed as corrosion products on steel," Hyperfine Interactions, vol. 112, pp. 59-65, 1998.

[48] F. Ospitali, D. C. Smith, and M. Lorblanchet, "Preliminary investigations by Raman microscopy of prehistoric pigments in the wall-painted cave at Roucadour, Quercy, France," Journal of Raman Spectroscopy, vol. 37, no. 10, pp. 1063-1071, 2006.

[49] L. Hao, S. Zhang, J. Dong, and W. Ke, "Evolution of atmospheric corrosion of $\mathrm{MnCuP}$ weathering steel in a simulated coastal-industrial atmosphere," Corrosion Science, vol. 59, pp. 270-276, 2012.

[50] M. Y. amashita, H. Uchida, and D. C. Cook, "Effect of $\mathrm{Cr}^{3+}$ and $\mathrm{SO}_{4}^{2-}$ on the structure of rust layer formed on steels by atmospheric corrosion," in Outdoor Atmospheric Corrosion, H Townsend, Ed., p. 149, West Conshohocken, PA, USA, ASTM International, 2002.

[51] D. C. Cook, S. J. Oh, R. Balasubramanian, and M. Yamashita, "The role of goethite in the formation of the protective corrosion layer on steels," Hyperfine Interactions, vol. 122, pp. 59-70, 1999.

[52] A. Manceau, M. L. Schlegel, M. Musso et al., "Crystal chemistry of trace elements in natural and synthetic goethite," Geochimica et Cosmochimica Acta, vol. 64, no. 21, pp. 36433661, 2000.

[53] Y. Tamaura and P. V. Buduan, "Studies on the oxidation of iron (II) ion during the formation of $\mathrm{Fe}_{3} \mathrm{O}_{4}$ and $\alpha-\mathrm{FeO}(\mathrm{OH})$ by air oxidation of $\mathrm{Fe}[\mathrm{OH}]_{2}$ suspensions," Journal of the Chemical Society, Dalton Transactions, no. 9, pp. 1807-1811, 1981. 


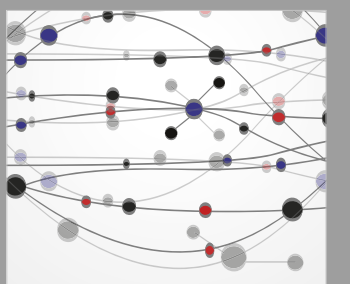

The Scientific World Journal
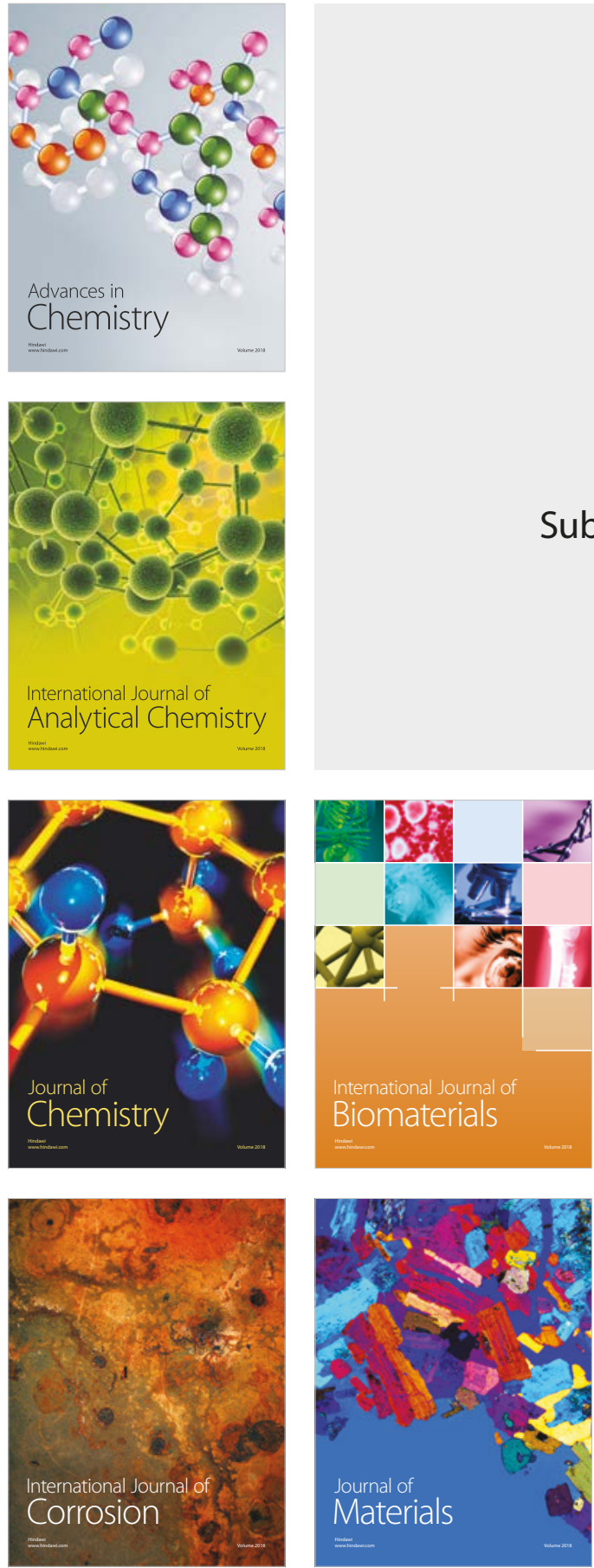

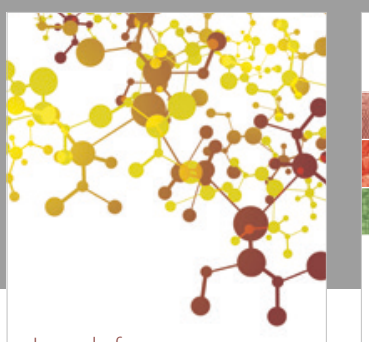

Journal of

Applied Chemistry
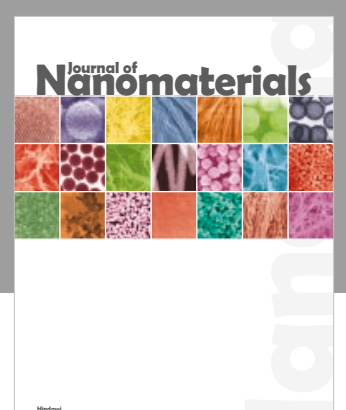

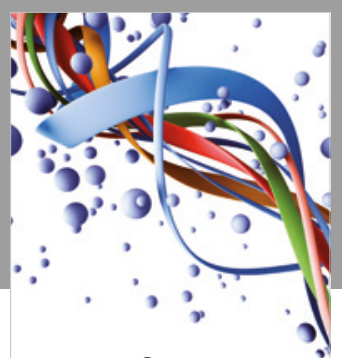

Scientifica

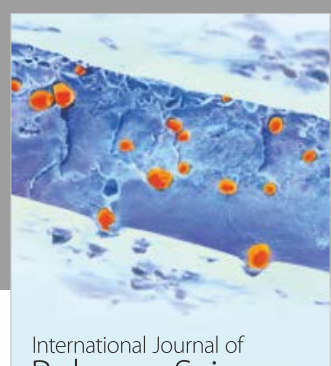

Polymer Science

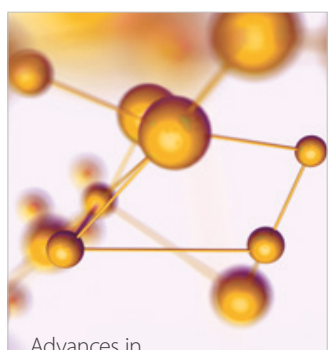

Physical Chemistry
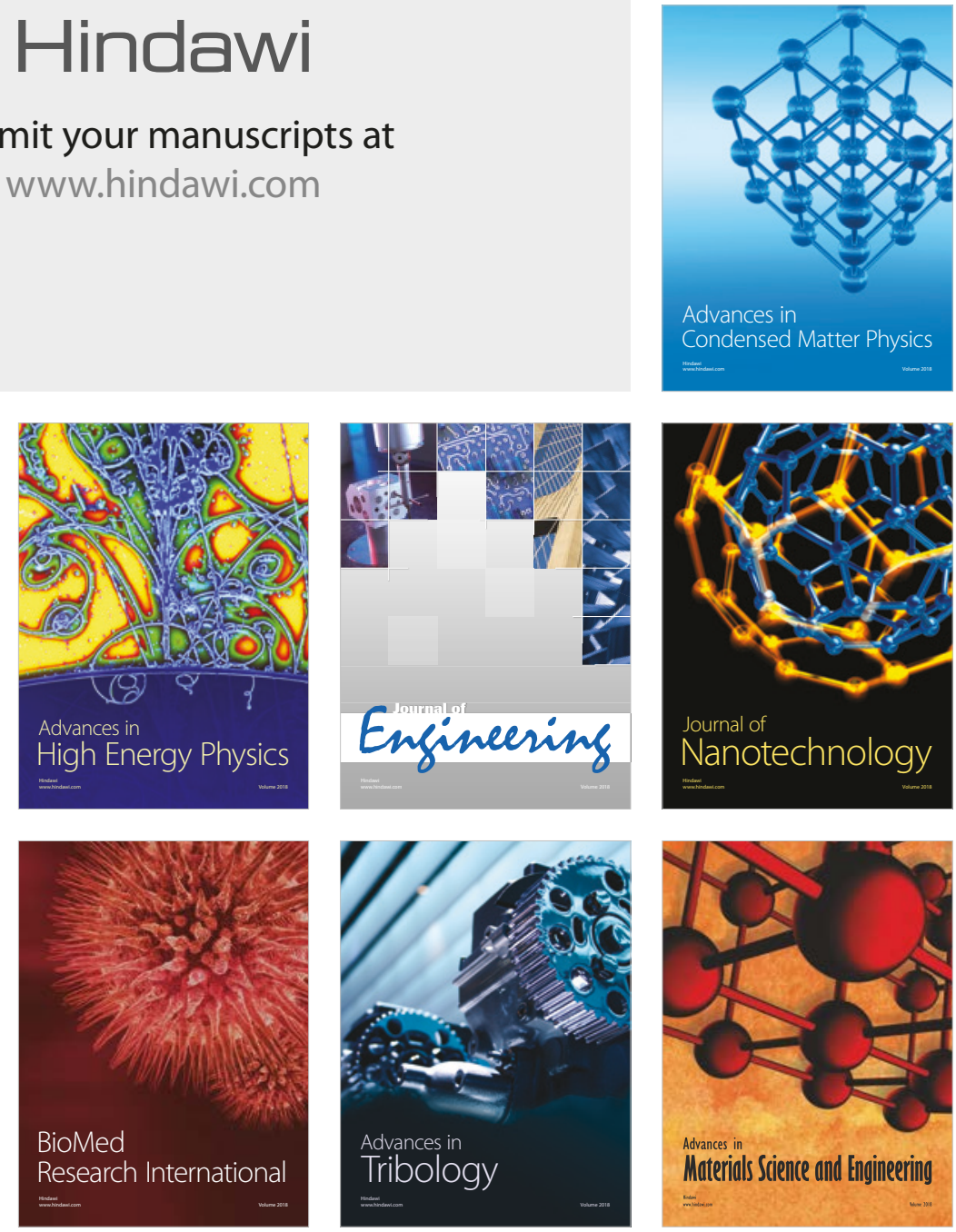